\title{
How is Students' Understanding in Resolving Questions Related to Derivative Concepts?
}

\author{
Lusiana Delastrii ${ }^{1, *}$, Purwanto $^{2}$, Subanji $^{2}$, Makbul Muksar ${ }^{2}$ \\ ${ }^{1}$ Mathematics Education, Universitas Kristen Indonesia Toraja, TanaToraja, Indonesia \\ ${ }^{2}$ Mathematics Education, Universitas Negeri Malang, Malang, Indonesia
}

Received September 16, 2020; Revised November 12, 2020; Accepted November 29, 2020

\begin{abstract}
Cite This Paper in the following Citation Styles
(a): [1] Lusiana Delastri, Purwanto, Subanji, Makbul Muksar, "How is Students' Understanding in Resolving Questions Related to Derivative Concepts?," Universal Journal of Educational Research, Vol. 8, No. 12A, pp. 7643 - 7650, 2020. DOI: 10.13189/ujer.2020.082550.
\end{abstract}

(b): Lusiana Delastri, Purwanto, Subanji, Makbul Muksar (2020). How is Students' Understanding in Resolving Questions Related to Derivative Concepts?. Universal Journal of Educational Research, 8(12A), 7643 - 7650. DOI: 10.13189/ujer.2020.082550.

Copyright $\bigcirc 2020$ by authors, all rights reserved. Authors agree that this article remains permanently open access under the terms of the Creative Commons Attribution License 4.0 International License

\begin{abstract}
Understanding is a cognitive ability that students must have. There are various ways to solve a question, it depends on the understanding that students have. When completing questions related to derivative concepts and graphically represented, students can solve them in different ways. This research aims to describe the characteristics of students who solve problems with conceptual and procedural understanding. This research is a qualitative study. The subjects of the study were two students who had different ways of resolving the problem. The supporting instrument used to dig up data is a task sheet whose contents are derivative questions. The results showed that the characteristics of students who solve problem with conceptual understanding are able to identify all information or concepts that can be used to solve the question, understand the definition of each concept that has been identified, able to associate all the information that has been identified in order to solve the question, and able to explain why the procedure used is correct to solve the problem. The student characteristics that solve the problem with procedural understanding are identifying some information contained in the problem, focusing only on the information used to construct the symbolic form, do not understand the information that has been identified, and relate concepts to one another, but it is meaningless. After reading this article, it is expected that teachers can choose the right learning method in teaching. Thus, both conceptual understanding and procedural understanding can be mastered by students.
\end{abstract}

Keywords Conceptual Understanding, Procedural Understanding, Derivative Concepts

\section{Introduction}

To develop understanding of derivative concepts is one of the main competencies in the learning Calculus. To understand the concept of derivatives, students must understand some other related concepts, such as line gradients, functions, limits, and continuations. Understanding means more than just knowledge of distinguishing syntax, having certain ideas when it is to construct concepts, as well as being able to use concepts inside and outside of mathematics. There are two types of understanding: Conceptual and procedural understanding [5], [13], [16], [21].

Conceptual understanding in mathematics is a comprehension of concepts, algorithms, and the relationship between several concepts. If faced with a derivative problem, student with a conceptual understanding must know the definition of a derivative, how to determine the derivative of a function, and know what concepts are related to the concept of derivatives and how they are related. Conceptual understanding involves the relationship between related concepts [25], understanding why procedures work, and whether they are valid [6],[32]. existing and new pieces of information or 
knowledge will form a complete knowledge network.

Procedural understanding involves knowledge of the rules and steps used to solve math problems. Procedural understanding is a comprehension that is centered on skills and stages of procedures without explicit references related to mathematical ideas [12], [18]. Hallett[13] describe procedural understanding as a process that involves manipulating symbols and routine rules. Someone who has procedural understanding tends to use procedures without knowing why they are used, in this case only relying on memorization [6]. Students who understand procedurally, only know how to determine derivatives of functions using rules without knowing what concepts are related to derivatives.

Conceptual and procedural understanding can increase as a person continues to practice solving problems. Completion of derivative problems is an individual process of implementing and combining knowledge (such as gradient lines, functions, limits, and continuations) previously obtained. In solving a derivative problem, it is more important to pay attention to the process than the final outcome. The answer that a person has given when completing a question should be noted where the answer is obtained, including the accuracy of the use of measures, rules and concepts [9], [19], [24]). The use of steps in resolving the problem shows that the solution is not easily obtained but must go through the procedure and be able to associate with existing concepts.

Conceptual and procedural understanding is crucial in resolving a question. When solving the problem, one needs a strategy to interpret and manipulate the information in analyzing and interpreting, as well as selecting the procedure and making the right decision with the ability to think [20], [10], [11], [14]. Some research suggests that success in solving mathematical problems is supported by conceptual and procedural understanding, such as [4], [7], [8], [19], [22].

The purpose of this research is to describe how the student's characteristics when solving the concept of derivative using conceptual and procedural understanding.

\section{Methods}

This research is a qualitative study in which the main data are taken from written and/or oral words. The research was conducted on 2 mathematics education students at one of the universities in TanaToraja, South Sulawesi. The research instruments are two, the main instruments and supporting instruments. The main instruments are researchers, because researchers themselves are collecting data through problem-solving tasks, interview and field records. Supporting instrument in the form of assignment sheet and interview guidelines. Figure 1 is the task sheet used.

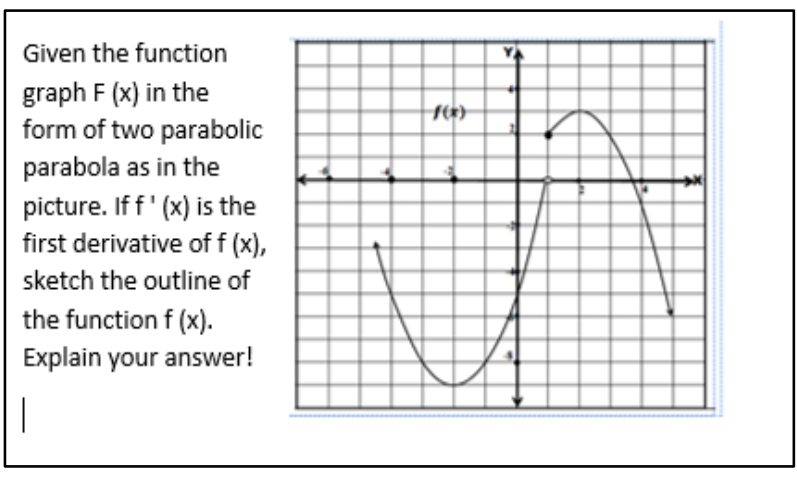

Figure 1. Task Sheet

\section{Results}

The first subject (S1) in this study was the subject that solved the problem using conceptual understanding. From the answer and the result of Think Aloud, S1 solved the problem related to the concept of derivative by using a gradient line that alludes to the curve $f(x)$. S1 identifies the information in the problem, such as the graph $f(x)$. consists of two parabolic (quadratic functions), several coordinate points passed through the curve, the local maximum and minimum points, the curve of curves, and the continuity of functions while pointing to the presented graphs. This is known from the result of the think-aloud of S1, which says:

S1: It is known that the graph The function $f(x)$ is a slice of two parabola (pointing at the graph). The first parabola opens up, I suppose $f_{1}(x)$. The local minimum point is $(-2,-9), f_{1}(x)$ is in the $x<1$, the monotone falls at the $x<-2$, and the monotone rises at the $-2<x<1$. The second parabola opens downward with a local maximum point $(2,3)$, is in the interval $x \geq 1$, monotone rises at the interval $1 \leq x<2$ and monotone falls at the interval $x>2$, and $f(x)$ is discontinuous at $x=1$.

This means that S1 understands all the information contained in the chart. Both parabola are symbolized by S1 as $f_{1}(x)$ located at intervals $x<1$ and $f_{2}(x)$ located at intervals $x \geq 1$. Furthermore, S1 also attempts to identify lines that offend $f(x)$, as in Figure 2. 


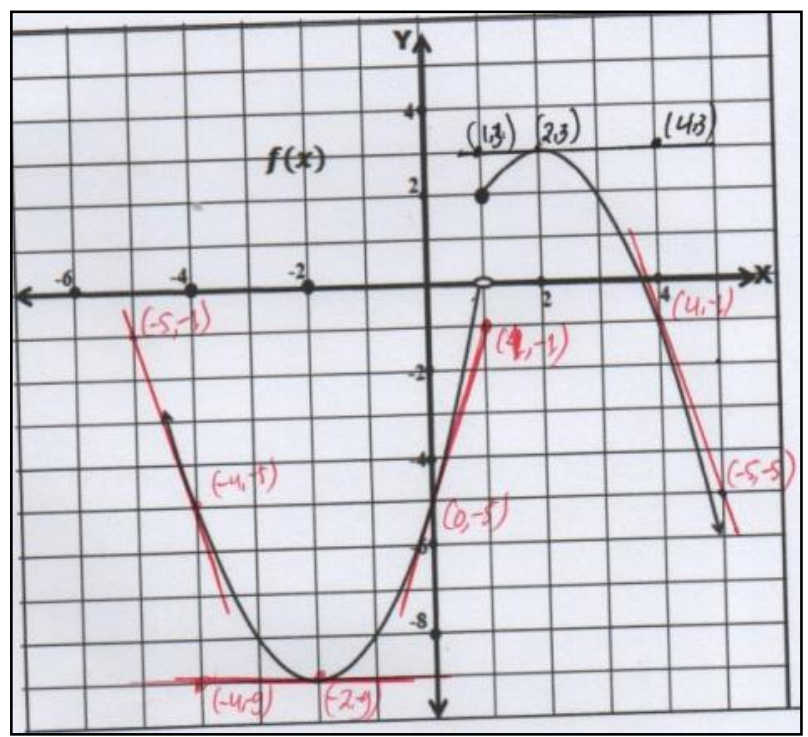

Figure 2. Outline of the curves $f(x)$ made by First Subject (S1)

The researcher (P) traced S1 understanding of information that has been identified, as seen in the following interview.

$P \quad$ : What do you know about the continuity of function $f(x)$ ?

S1 : An $f(x)$ function is said to be continuous at the time of $x=c$, if $\lim _{x \rightarrow c} f(x) \nabla$ exists, $f(c)$ exists, and $\lim _{x \rightarrow c} f(x)=f(c) . f(x)$ continuous at all points at intervals $x<1$ and Interval $x \geq 1$.

$P \quad$ : Why did you say $F(x)$ discontinuous at $x=1$ ?

S1 : As $\lim _{x \rightarrow 1^{-}} f(x) \neq \lim _{x \rightarrow 1^{+}} f(x)$

$P \quad$ : What do you know about the monotony function curve?

S1 : Suppose there is a function $f(x)$

$f(x)$ says monotonous rises if $x_{1}<x_{2} \rightarrow f\left(x_{1}\right)<$ $f\left(x_{2}\right)$

Example on the graph $f(x)$ (while pointing to the graph on the task sheet), $x_{1}=-1<x_{2}=0 \rightarrow$ $f(-1)=-8<f(0)=-5)$.

$f(x)$ is said to be monotonous down if $x_{1}<x_{2} \rightarrow$ $f\left(x_{1}\right)>f\left(x_{2}\right)$.

Example on the graph $F(x)$ (while pointing to the graph on the task sheet), $x_{1}=3<x_{2}=4 \rightarrow$ $f(3)=2>f(4)=-1)$.

Based on the result of interview above, it can be concluded that S1 understands the concept of continuity and monotony function.

When completing the question related toderivative concept, S1 uses a line gradient that alludes to the curve $f(x)$ at one point, as seen in Figure 3. S1 understands that in geometry, the line gradient that alludes to the curve $f(x)$ at a certain point is a derivative value of $f(x)$ function at that point.

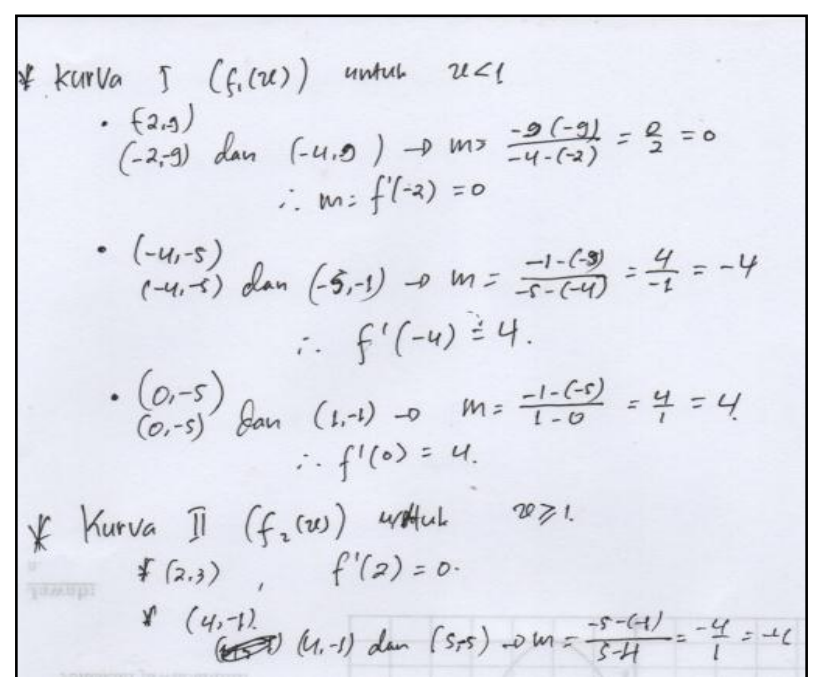

Figure 3. First Subject (S1) steps to solve the problem

$\mathrm{S} 1$ also coordinates the continuity of the function of the first derivative value. This can be seen from the results of S1 Think Aloud.

S1: $f(x)$ discontinuous at $x=1$ so that the offensive line $f(x)$ at the time $x=1$ does not exist, thus $f(x)$ does not have a gradient or does not have the first derivative value at $x=1$.

Based on the above statement, S1 concluded that the derivative value $f(x)$ at the time $x=1$ does not exist because $f(x)$ discontinuous at $x=1$. S1 could not make the curve tangent at the time $x=1$. S1 understands that a function that has the first derivative value at a certain point, continuous at that point.

$\mathrm{S} 1$ does not directly relate to the gradient of tangent lines with the curves monotony, but S1 understands the relationship between function with derived value function. It can be seen in the interview result between the researcher (P) with the second subject (S1) as follows.

$P \quad$ : In your Think Aloud results (listening to recordings), you mention the monotony curve. Can you explain the relationship between the monotony curves of a function with a derived value function?

S1 : (While pointing to the graph $f^{\prime}(x)$ that has been created) in this section.

At intervals of $x<-2$, the derivative value is negative because it is below the $X$ axis. If it is associated with the previous curve of $f_{1}(x)$, the $f_{1}(x)$, curve of monotonous drops at intervals $x<-2$.

$f^{\prime}(-2)=0$ as it is the local minimum point of the $f_{-}$l curve $f_{1}(x)$.

At $-2<x<1$ the derivative value is positive because it is above the $X$ axis. When associated with the previous curve of $f_{1}(x)$, the $f_{1}(x)$ curve of monotonous rises at intervals of $-2<x<1$. 
At $1 \leq x<2$, the derivative value is positive because it is above the $X$ axis. If it is associated with the previous curve of $f_{2}(x)$, curve $f_{2}(x)$ monotonous rises at intervals of $1 \leq x<2$. $f^{\prime}(2)=0$ obcause it is the local maximum point of the curve $f_{2}(x)$

At $x>2$ the derivative value is negative, if associated with the previous curve or $f_{2}(x)$, the curve $f_{2}(x)$ monotonous down at intervals $x>2$.

$P \quad$ : Can you provide an example of the relationship between a monotony curve with a derivative value at one point?

S1 : On curve $f_{1}(x) \ldots \ldots . .$. The dot $(0,-5)$ is at the interval of $-2<x<1$ which is when the curve $f_{1}(x)$ monotonous rises, if I make a tangent line, the line is angled to the right or up from left to right. Thus the value of the gradient or the first derived value of a positive value function is $f_{1}^{\prime}(0)=4$. The dots $(4,-1)$ are in the interval $x>2$ i.e. when the monotonouscurve $f_{2}(x)$ down, if I make a tangent line, then the line is angled left or down from left to right. Thus the gradient value or the first derivative value of a negative value function is $f_{2}^{\prime}(4)=-4$.

In the results of the above interviews, $\mathrm{S} 1$ understands that a negative or positive sign on the gradient or the first derivative value of a function at a certain point is associated with a function monotony. If the monotonous function rises, then the gradient value or derivative value of the function is positive. If the monotonous function goes down, then the gradient value or derivative value of the function is negative. S1 also associates the first derivative value $f(x)$ function with the local maximum and minimum points and tangent curves.

The second subject (S2) in this study was a subject that solved the problem using understanding procedural. Based on the answers and the Think Aloud results, the second subject began to solve the question by reading the problem. S2 strives to understand the $f(x)$ chart by observing the $f(x)$ chart presented. The subject resolves an issue in a task sheet by using a symbolic form of function. The picture below is S2's answer to the question.

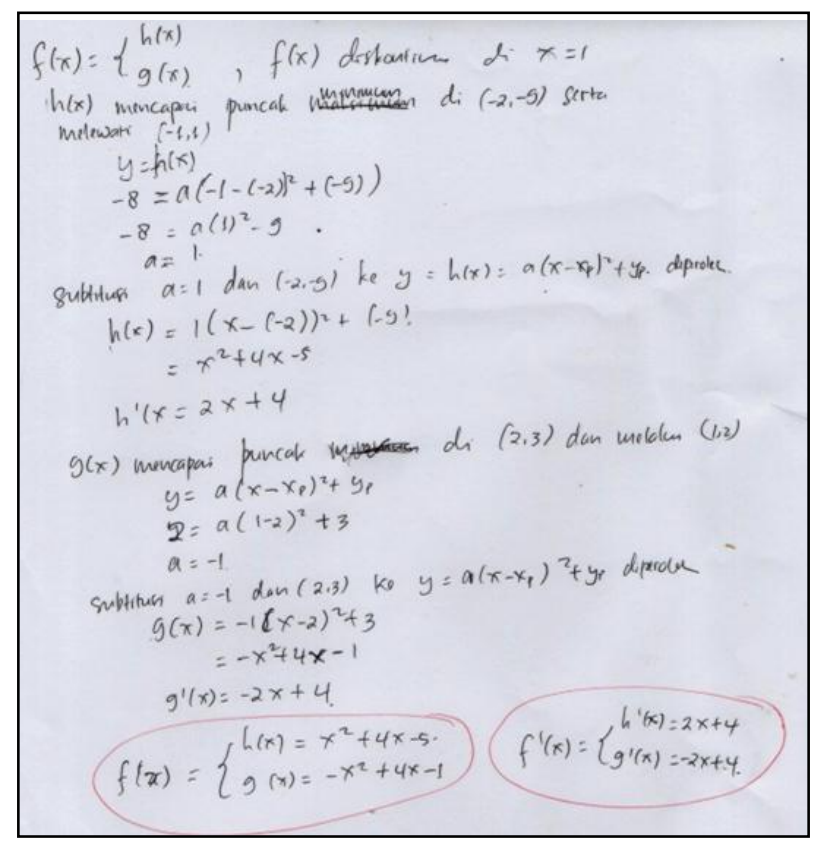

Figure 4. Second Subject (S2) Answers to the Problem

S2 states Graph $f(x)$ is a slice of two parabolic dish i.e. $f(x)=\left\{\begin{array}{l}h(x) \\ g(x)\end{array}\right.$, and $f(x)$ discontinuous at $x=1$. Furthermore, S2 identifies the points that are traversed $h(x)$ and $g(x)$.The $h(x)$ function reaches the minimum peak at the point $(-2,-9)$ and passes $(-1,-8)$. The $g(x)$ function reaches the maximum peak at the point $(2,3)$ and passes $(1,2)$.

To further explore S2's understanding of the information in the question, researchers conducted the following interview.

$P \quad$ : You say that $f(x)$ discontinues at $x=1$. What can you explain about the continuity of the function?

S2 : If it is not wrong... The limitation value is exist.

$P \quad$ : Can you tell me about "the existing of limitation value"?

S2 : Iforgot it.

$P \quad$ : Why did you say $f(x)$ is not continuous at $x=$ 1 ?

S2 : Because the shape is like in the picture. 
Based on the interview result above, S2 realized that $f(x)$ was not continuous at $x=1$ but was unable to explain about it. S2 does not understand the concept of function continuity.

S2 resolves the problem by using the general form of quadratic function $y=a x^{2}+b x+c$. From Figure 3, S2 managed to find the symbolic form of the graph is $f(x)=\left\{\begin{array}{c}h(x)=x^{2}+4 x-5 \\ g(x)=-x^{2}+4 x-1\end{array}\right.$, but didn't pay attention to the interval limit for each function To trace the second subject's understanding of the function concept, the researcher conducted the following interview.

$P \quad$ : What kind of things that we must be aware of when writing a function?

$S 2 \quad$ : There is an $X$ variable as a free variable and $y=f(x)$ as a bound variable.

$P \quad:$ What are some other things to be aware of?

S2 : No more.

From the interview excerpt, S2 does not understand the concept of function. S2 only knows that the function consists of free variables and bound variables.

To sketch the chart $f^{\prime}(x)$, S2 began by observing the derivative function $f^{\prime}(x)=\left\{\begin{array}{c}2 x+4 \\ -2 x+4\end{array}\right.$, which was obtained, further S2 identified $x$ in function $f^{\prime}(x)$. Here is the graph $f^{\prime}(x)$ that has been created S2.

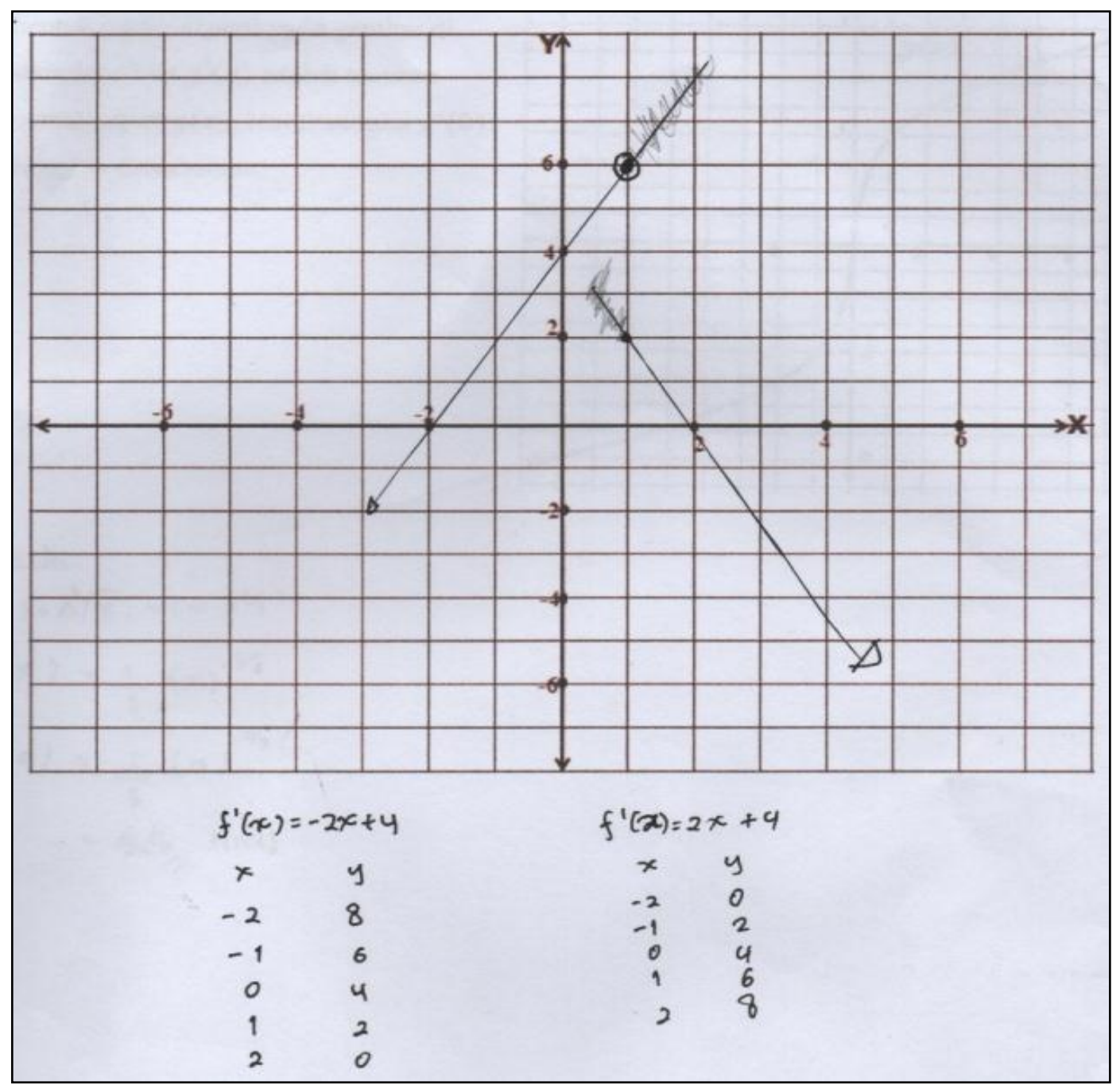

Figure 5. Graph of Function $f^{\prime}(x)$ Created by Second Subject (S2) 
Based on Figure 5, S2 identifies the $x$ variables that will be substituted to the $f_{1}^{\prime}(x)$ and $f_{2}^{\prime}(x)$ regardless of the domain interval limit of function $x<1$ and $x \geq 1$.

The following interview was done to know the understanding of S2 about the relationship between the continuity of function with the value of derivative function.

$P \quad:$ Can you associate the concept of continuity with derivatives?

S2 : A function which is not continuous at a point has no derivative. For example, $f(x)$ is not continuous at $x=1$, then $f(x)$ has no derived value at $x=1$.

$P \quad:$ Why does $f(x)$ not have a derived value in $x=1$ ?

S2 : Because it is not continuous.

$P \quad$ : Do you think "every function which continues at a point will have a derived value"?

S2 : Yes.

From the interview excerpt, $\mathrm{S} 2$ realized the existence of derivative value of function with continuity of function but couldn't to explain the relationship between them meaningfully. S2 does not understand that a function that has a value of the first derivative at a certain point, then the function is continuous at that point. However, it is not vice versa. A function which continues at a certain point, does not necessarily have a derivative value at that point.

\section{Discussion}

The first subject (S1) begins to resolve the problem by reading and identifying all the key information or concepts that can be used to define derivative values at some point. The information is the graph $f(x)$ is a piece of two parabola where the first parabola is at intervals $x<1$ and the second parabola is at intervals $x \geq 1$, the local maximum and minimum points, monotony function curve, and continuity of function. S1 also identifies other concepts related to derived concepts, which are the lines that offend the function curve $f(x)$ at a point. S1 is able to define any information or concepts identified. One characteristic of a person with conceptual understanding is being able to define the concept [6], [8], [18], [22]. S1 also understands that geometry, the line gradient that alludes to the curve $f(x)$ at a point in geometry equals to the value of derivative function at that point. Based on the description, it can be said that the student solves the problem of using conceptual understanding to understand each information that will be used to resolve the problem. A thorough understanding of the underlying concepts and being reversed algorithms that are done to resolve the problem is characteristic of conceptual understanding [7], [10], [25].

The second subject (S2) as a student who solved the problem using procedural understanding revealed that the graph of function $f(x)$ is a piece of two parabola without regard to the interval limit for each parabola. S2 also identifies the variable $x$ as the domain to be closed to $f^{\prime}(x)$ regardless of the interval limit of functions i.e. $x<1$ and $x \geq 1$. This suggests that students who resolve questions using procedural understanding only focus on the problem formula or symbolic form of the problem and ignore the function's interval or domain function limit. The tendency of a person oriented to memorization of procedures and manipulation of symbols is usually not supported by the understanding of the concepts involved ([14], [28]). Students with a procedural understanding lack of understanding of any information/concepts that have been identified, and do not understand that any information can be used and related to the new concept as a form of problemssolving. S2 only knows the symbolic form of function concept without regard to the terms/properties of functions. S2 is also able to identify the concept of continuity of functions but does not understand the concept. Without any understanding of the underlying concepts of the rules, one can produce the correct answer if followed by gradual steps [23]. Furthermore, S1 and S2 process the information that has been identified to design a problem solving strategy. S1 used a tangent gradient. S1 knows why using the concept when specifying a value of a derived function and sketched the chart $f^{\prime}(x)$ A person with conceptual understanding usually knows the concepts involved in the matter, also know why to use the concept [6]. While S2 only knows and uses the symbolic form of the graph of functions. Someone with a procedural understanding tends to be familiar with the symbols and procedures/rules for solving mathematical problems [17], [29]

Students with conceptual understanding understand the link between all the information/concepts that have been identified with the new concept as a form of problem solving. It is in accordance with the opinion [2], [3], [26], [27] that conceptual understanding involves the relationship between the related concepts. The involvement of such relationships can form a network of knowledge. The first subject understands the link between the tangent gradient, the local minimum and maximum points, the continuity of the function with the derived value of the function. The tangent $f(x)$ when reaching the local minimum and maximum points is a line that aligns with the $\mathrm{x}$-axis or horizontal line, so the derived value of the function at the time is zero. S1 understands the linkage between tangent curves, monotony curves and derived value of functions. The tangent line on the function curve that monotonous down has a line gradient or derivative function that is negatively valued. The tangent on the curve of the function of a monotonous rise has a gradient line or derivative function that is positive value. Then $\mathrm{S} 1$ also understands the relationship between the continuity of functions with the value of derivative functions. By associating the concept of a tangent gradient at a certain point, the continuity of the function, the 
modernity of functions with derivative concepts, a person demonstrates a complete understanding of the concept of derivative functions [25]

The second subject (S2) knows the relationship or linkage between the continuity of function and the derivation of the function, but does not understand that a function that has a derivative value at a certain point then the function is continuous at that point, but not vice versa. In this case, it is unable to associate concepts meaningfully. With the basic knowledge of individuals about concepts, meaningful relationships between concepts can be built, but some individuals can gain a lot of knowledge about concepts, but they cannot relate them meaningfully

\section{Conclusions}

Problems related to derivative concepts and graphically represented can be solved in two ways, depending on someone's understanding. Students with conceptual understanding resolve problems using a line gradient, but it is also possible that they use symbolic shapes. While the students who understand procedural only know how to solve the problems that are represented graphically using symbolic shapes or equation shapes. The student characteristics that solve the problem with conceptual understanding are 1) able to identify all information or concepts that can be used to solve the problem, 2) understand the definition of each concept that has been identified, 3) able to associate all the information that has been identified in order to solve the problem. With the problem-solving procedure using gradient lines, a student with a conceptual understanding can explain why using the procedure to solve the problem. The student characteristics of procedural understanding are1) identifying only some of the information contained in the problem, focusing only on the information used to construct the symbolic form. 2) lack of understanding information that has been identified, 3) relate concept one another, but it is meaningless.

Success in solving math problems is supported by ideas that allow deep understanding. On a deep understanding, students begin to be able to make connections between mathematical ideas and make generalizations from concepts, equipped with basic skills that have been understood. Deep understanding includes both procedural and conceptual understanding. Conceptual and procedural understanding helps students avoid many critical mistakes in solving problems.

\section{Acknowledgments}

The author thanks to The Department Mathematics Education, Faculty of Teacher Training and Education, Universitas Negeri Malang and Universitas Kristen
Indonesia Torajafor supporting this research.

\section{REFERENCES}

[1] Abdullah, S. A. S. Comprehending the concept of functions. Procedia - Social and Behavioral Sciences, 8(5), 281-287. 2010. https://doi.org/10.1016/j.sbspro.2010.12.038.

[2] Bartell, T. G., Webel, C., Bowen, B., \& Dyson, N.. Prospective teacher learning: Recognizing evidence of conceptual understanding. Journal of Mathematics Teacher Education, 16(1), 57-79. 2013. Https://doi.org/10.1007/s10 $857-012-9205-4$

[3] Bisson, M.-J., Gilmore, C., Inglis, M., \& Jones, I. Measuring Conceptual Understanding Using Comparative Judgement. International Journal of Research in Undergraduate Mathematics Education, 2(2), 141-164. 2016. Https://doi.org/10.1007/s40753-016-0024-3

[4] Castro-Rodríguez, E., Pitta-Pantazi, D., Rico, L., \& Gómez, P. Prospective teachers' understanding of the multiplicative part-whole relationship of fraction. Educational Studies in Mathematics, 92(1), 129-146. 2016. Https://doi.org/10.100 7/s10649-015-9673-4

[5] Chapman, O. Mathematical-task knowledge for teaching. Journal of Mathematics Teacher Education, 16(1), 1-6. 2013. https://doi.org/10.1007/s10857-013-9234-7.

[6] Chinnappan, M., \& Forrester, T. Generating procedural and conceptual knowledge of fractions by pre-service teachers. Mathematics Education Research Journal, 26(4), 871-896. 2014. https://doi.org/10.1007/s13394-014-0131-x

[7] Delastri, L., Purwanto, Subanji, \& Muksar, M. Students' conceptual understanding on inverse function concept. Journal of Physics: Conference Series, 1157(4). 2019. https://doi.org/10.1088/1742-6596/1157/4/042075

[8] Donevska-todorova, A., \& Donevska-todorova, A. Conceptual Understanding of Dot Product of Vectors in a Dynamic Geometry Environment Conceptual Understanding of Dot Product of Vectors in a Dynamic Geometry Environment, 9(September). 2015.

[9] Donevska-todorova, A., \& Donevska-todorova, A. Procedural and Conceptual Understanding in Undergraduate Linear Algebra Algebra, (June).2016.

[10] Engelbrecht, J., Harding, A., \&Potgieter, M. Undergraduate students performance and confidence in procedural and conceptual mathematics. International Journal of Mathematical Education in Science and Technology, 36(7), 701-712. 2005. https://doi.org/10.1080/0020739050027110 7

[11] Habre, S., \& Abboud, M. Students' conceptual understanding of a function and its derivative in an experimental calculus course. Journal of Mathematical Behavior, 25(1), 57-72. 2006. Https://doi.org/10.1016/j.jma thb.2005.11.004

[12] Hallett, D., Nunes, T., \& Bryant, P. Individual Differences in Conceptual and Procedural Knowledge When Learning Fractions. Journal of Educational Psychology, 102(2), 
395-406. 2010a. https://doi.org/10.1037/a0017486

[13] Hallett, D., Nunes, T., \& Bryant, P. Individual Differences in Conceptual and Procedural Knowledge When Learning Fractions. Journal of Educational Psychology, 102(2), 395-406. 2010b. https://doi.org/10.1037/a0017486

[14] Hiebert, J., \&Lefevre, P. Conceptual and procedural knowledge in mathematics: The Case of Mathematics. Conceptual and Procedural Knowledge: The Case of Mathematics, 5(3), 1-27. 1986. https://doi.org/10.12691/education-5-3-12

[15] Jin, H., \& Wong, K. Y. Mapping Conceptual Understanding of Algebraic Concepts: an Exploratory Investigation Involving Grade 8 Chinese Students. International Journal of Science and Mathematics Education, 13(3), 683-703. 2015. https://doi.org/10.1007/s10763-013-9500-2

[16] Karlova, U., \& Pedagogicka, P. Structural Understanding in Advanced Mathematical Thinking Nad' a Stehlı' kova. 2004.

[17] Khashan, D. K. H. Conceptual and Procedural Knowledge of Rational Numbers for Riyadh Elementary School Teachers. Journal of Education and Human Development, 3(4), 181-197. 2014. https://doi.org/10.15640/jehd.v3n4a17.

[18] Lovin, L. A. H., Stevens, A. L., Siegfried, J., Wilkins, J. L. M., \& Norton, A. (2018). Pre-K-8 prospective teachers' understanding of fractions: An extension of fractions schemes and operations research. Journal of Mathematics Teacher Education, 21(3), 207-235. 2018. https://doi.org/1 $0.1007 / \mathrm{s} 10857-016-9357-8$

[19] Marchionda, H. Preservice teachers' procedural and conceptual understanding of fractions and the effects of inquiry-based learning on this understanding. ProQuest Dissertations and Theses, $185-185$ p. 2006 . Retrieved from https://login.ezproxy.net.ucf.edu/login?url=http://search.pro quest.com/docview/305358295 ?accountid=10003\%5Cnhttp ://sfx.fcla.edu/ucf?url_ver=Z39.88-2004\&rft_val_fmt=info: ofi/fmt:kev:mtx:dissertation \&genre=dissertations+\%26+the ses\&sid=ProQ:ProQuest+Disserta

[20] Mills, S. Conceptual Understanding: A Concept Analysis Conceptual Understanding: A Concept Analysis. The Qualitative Report, 21(3), 546-557. 2016. Retrieved from http://nsuworks.nova.edu/cgi/viewcontent.cgi?article $=2308$ \&context $=$ tqr

[21] Nor Hasnida, C. G., \& Effandi, Z. Students' Procedural and Conceptual Understanding of Mathematics. Australian Journal of Basic and Applied Sciences, 5(7), 684-691. 2011.

[22] Perkins, D. The Teaching for Understanding Framework. The Teaching for Understanding Guide. San Francisco: Jossey-Bass, 17-24. 1998. Retrieved from http://artised.m7
sandbox.com/sites/default/files/3frameworks.pdf\%5Cnpape rs2://publication/uuid/C325D218-53CA-4176-88C6-ED313 610AACC

[23] Rittle-Johnson, B., \& Alibali, M. W. Rittle-Johnson \& Alibali 1999 Conceptual and Procedural Knowledge of Mathematics - Does One Lead to the Other.pdf, 91(1), 175-189. 1999. https://doi.org/10.1088/1742-6596/90/1/01 2030

[24] Rittle-Johnson, B., \& Schneider, M. Developing Conceptual and Procedural Knowledge of Mathematics. Oxford Handbook of Numerical Cognition, 1118-1134. 2014. https://doi.org/10.1093/oxfordhb/9780199642342.013.014

[25] Rittle-Johnson, B., Schneider, M., \& Star, J. R. Not a One-Way Street: Bidirectional Relations Between Procedural and Conceptual Knowledge of Mathematics. Educational Psychology Review, 27(4), 587-597. 2015. https://doi.org/10.1007/s10648-015-9302-x

[26] Rittle-Johnson, B., Siegler, R. S., \& Alibali, M. W. Developing conceptual understanding and procedural skill in mathematics: An iterative process. Journal of Educational Psychology, 93(2), 346-362. 2001. https://doi.org/10.1037/ 0022-0663.93.2.346

[27] Salleh, T. S. A., \&Zakaria, E. The development and validation of conceptual and procedural understanding test for integral calculus. Research Journal of Applied Sciences, Engineering and Technology, 4(12), 1805-1814. 2012.

[28] Shahbari, J. A., \&Peled, I. Modelling in Primary School: Constructing Conceptual Models and Making Sense of Fractions. International Journal of Science and Mathematics Education, 15(2), 371-391. 2017.https://doi.org/10.1007/s1 0763-015-9702-x.

[29] Singer, F. M., \& Voica, C. A problem-solving conceptual framework and its implications in designing problem-posing tasks. Educational Studies in Mathematics, 83(1), 9-26. 2013. https://doi.org/10.1007/s10649-012-9422-x

[30] Siyepu, S. W. Analysis of errors in derivatives of trigonometric functions. International Journal of STEM Education, 2(1). 2015. https://doi.org/10.1186/s40594-0150029-5

[31] Voutsina, C. Procedural and conceptual changes in young children's problem solving. Educational Studies in Mathematics, 79(2), 193-214. 2012. Https://doi.org/10.100 7/s10649-011-9334-1.

[32] Zhang, X., Clements, M. A. (Ken., \& Ellerton, N. F. (2015). Conceptual mis(understandings) of fractions: From area models to multiple embodiments. Mathematics Education Research Journal, 27(2), 233-261. 2015. https://doi.org/10. 1007/s13394-014-0133-8 